\title{
On nova Scorpii 2007 N.1 (V1280 Sco)
}

\author{
Hanindyo Kuncarayakti • Desima Kristyowati • \\ Chatief Kunjaya
}

Published online: 28 March 2008

(C) Springer Science+Business Media B.V. 2008

\section{Erratum to: Astrophys Space Sci}

DOI 10.1007/s10509-008-9756-0

The authors of this paper noted in paragraph 3.1 that AAVSO is the abbreviation of American Amateur Variable Star Observer. As can be concluded from the website of the AAVSO (http://www.aavso.org), it is the abbreviation of the American Association of Variable Star Observers.

The authors are deeply sorry for this error.

The online version of the original article can be found at doi:10.1007/s10509-008-9756-0.

H. Kuncarayakti $(\bowtie) \cdot$ D. Kristyowati · C. Kunjaya Bosscha Observatory \& Department of Astronomy, Institut Teknologi Bandung, Bandung, West Java 40134, Indonesia e-mail:kuncarayakti@gmail.com 